$\xi=-1$

\title{
Study of Illumination Optical System to Control Light Pollution due to Night Lighting
}

\author{
Kyung-Sun Yoo ${ }^{1}$, Soo-Young Lee ${ }^{* 1}$, Dong-Hoon Hyun ${ }^{1}$, Byoung-Jo Jung ${ }^{2}$ \\ ${ }^{1}$ Korea Polytechnic University, Siheung - si, Republic of Korea, 15073 \\ ${ }^{2}$ Department of Lift Engineering, Korea Lift College, Geochang - gun, Republic of Korea, 50141 \\ *Corresponding author E-mail: syuo1119@naver.com
}

\begin{abstract}
Background/Objectives: Artificial light has developed with both sides of light pollution. International organizations recognize the seriousness of light pollution and are offering ways to make restrictions light pollution.

Methods/Statistical analysis: It padded an additional surface on the back of the lens to convert the light to the House side into a street side. The slope of the additional surface was determined by the angle of the light that emerged from the LED.As a result, it implemented B1 rating of security light on BUG Rating defined by IESNA.

Findings: The total internal reflection of the lens was used to control the posterior light. The inner surface was set to totally reflect the light directed toward the house side inside the lens, and the inclination of the outer surface was set so that the light refracted from the outer surface and directed forward when the light exits. As a result of controlling the backlight in this way, the B1 light distribution classified by the BUG rating was implemented. It also made the ratio of light from Street side to House side about 8:2.

Improvements/Applications: When applying the expression proposed in this paper to the streetlight optical system, it can complement the light pollution problem.
\end{abstract}

Keywords: Street side, House side, Light pollution, Backlight, Freeform, Internal total reflection

\section{Introduction}

The development of artificial lighting has changed the night more brilliantly, and it provides convenience for nighttime activities like daytime. However, at present, in Korea the seriousness of light pollution is pointed out in the installation trend of lighting installing only brighter than the surroundings without considering harmony with the surrounding light environment. Along with the rapid development of industries and technologies, the pollution caused by light more than necessary generated by human beings is defined as light pollution.

To understand how light may affect humans, it is ideal to realize first how light is introduced into body and how it used by the body. Light pollution affects human bodies and ecosystems, interferes with astronomical observations, skylights are a factor in energy waste. Other than the radical issue of sky glow caused by artificial lighting[1], light pollution is also the cause of a number of know ecological concerns. Among the know effects, health issues in humans caused by exposure to artificial lighting at night are the most pressing. Some of the light is then used for vision whereas the rest of the light mediates in other human biological processes, such as the synchronization of the light and dark cycles. In this case, damage of light pollution in humans could also be divided into 2 categories; the image forming effects and the nonimage forming affects. The image forming problems are associated with disability glare of artificial light. These have been indicated to be a contributing force to the occurrence of both types of glare; discomfort and disability glare[2]. The non-image forming effects are mainly due to a disrupted circadian rhythm-an internal clock that regulates most of the physiological systems in mammals[3]. The peak secretion of melatonin has been reported to be between midnight and 4 a.m. in the morning[4]. Thus exposure to artificial light during this period inhibits the production of melatonin and thus a disruption of the entire circadian cycle. It has been linked to simple discomforts such as fatigue[5], reduced work productivity[6].

The aim of light pollution laws is generally to permit reasonable usage of artificial lighting for safety, utility, and security, while minimizing the degradation of the nighttime visual environment and the night sky. The endeavors to develop regulations for light pollution reduction are also usually linked to questions of energy efficiency and or cityscape aesthetics[7]. The Illuminating engineering society and the International Dark-sky Association(IDA) joined together and established common regulations to be used as guidelines for preventing light pollution, the Model Lighting Ordinance[8].The Korean government spent a period of 4years, from September 2009 when the bill of the light pollution was submitted to the assembly to December 2011 when the bill was passed, debating all possible actions to prevent light pollution caused by excessive ALAN(Artificial Lighting At Night)[9]. Finally [Light Pollution Prevention Law by Artificial Lighting] was enacted, giving a grace period of 5 years for conventional lighting equipment and observing light emission tolerance standards in February 2013. In order to prevent light pollution, movements are being promoted for each region, but there are provisions only, no specific alternative of products has been established.

In the case of security and the like installed in the residential, walking space, in most cases it is located without considering the optical characteristics, complaints such as invasion of residence by 
light, induction of glare etc. remain constant.

\section{Freeform Lens Design}

This design relates to a lens applied to a $\mathrm{COB}$ (Chip on Board) LED, which is a surface light source belonged to LED street light capable of backlight control. Generally, in order to control the backlight of street light, the lighting adds the reflector which reflects the light going backwards. However, there are some disadvantages when controlling the light using a reflector plate in this way. First, as the reflector is fabricated, an additional fee is generated and it is difficult to control the light in the desired direction. When reflecting plate is arbitrarily placed to reflect light and make go forward, the light distribution graph formed by the existing LED street light is changed and the uniformity and glared of light illuminating the road surface can be changed. Finally, since the reflectance of the reflector cannot be $100 \%$, the efficiency is lost as the backward light is reflected. As a result the brightness of the total luminous flus of the illumination decreases. Due to these drawbacks, it is very important to control the backlight using only the optical system to control the light pollution, which is a great advantage in the current lighting industry.

The shape of the lens can be seen in detail in the figure 1 , the structure is formed by continuously connecting convex free-form surfaces having ridges on the front body and the rear body. The rear body is a specially added curved surface for controlling the backlight. Inner surface of the lens is formed as a free-form surface so as to have a recessed shape toward the outer surface at the central portion of the optical system. An optical system for controlling the rear light by totally reflecting the emitted light of the COB type LED which is formed as a free-form surface so as to have a recessed shape toward the outer surface and which moves backward, behind the optical system.

Light is emitted from the center of the COB type LED as the surface light source, the initial formation angle reached to the rear of the light distribution control unit is set to " $\alpha$ ". The angle formed between the light reaching the backlight control unit in the lens and the free-form surface of the backlight control unit, which is a portion marked with $\mathrm{C}$, is set to " $\beta$ ". The angle formed between the light refracted forward and the outer surface $\mathrm{B}$ after being totally reflected by the free curved surface of $\mathrm{C}$ and reaching the free curved surface B behind the outer surface is defined as " $\gamma$ ". Angles are set as described above, and the values of $\beta$ and $\gamma$ set when the value of $\alpha$ is $9^{\circ}, 18^{\circ}, 27^{\circ}$. The ray emanating from the LED vertically passes through the first surface inside the optical system and determines the inclination of the first surface of the optical system so that the value of $\alpha$ is constant. Let's look at the direction of the ray in Figure 2 afterwards. The incident angle when the ray is incident on the c-plane is set to " $i$ ". At this time, ray is totally reflected by the surface $\mathrm{C}$, the direction of the light diverging in the House side direction can be changed to the Street side by being refracted from the surface $\mathrm{B}$. The conditions of the slope values of surfaces $\mathrm{C}$ and $\mathrm{B}$ should be set so that the light path can proceed in this way.

First, in order for total reflection to occur, the incident angle must be larger than the total internal reflection critical angle. The total internal critical angle can be obtained through Snell's law. The material of the optical lens used in this study is plastic PMMA and its refractive index is 1.49 . It will not discuss the critical angle of total internal reflection through Snell's law. $\beta$ must be less than 48 - because the incident angle $i$ must be greater than the critical angle of $42^{\circ}$. Second, the value of $\beta$ must be greater than $\mathrm{x}$ in order for the ray totally reflected on surface $\mathrm{C}$ to be refracted on surface $\mathrm{C}$ and to be directed to the street side. The relationship between $\alpha, \beta$ and $\mathrm{x}$ is shown in Fig., The equation of $\beta+\mathrm{x}=81^{\circ}$ can be obtained when the first assumption $\alpha=9^{\circ}$. At this time, as mentioned above, the second condition $\beta$ should be larger than $40.5^{\circ}$ because the value of $\beta$ must be larger than $\mathrm{x}$ in order to direct the ray to Street side. With this approach, the shape of the lens was defined by determining the inclination of the corresponding lens surface when $\alpha=9^{\circ}, \alpha=18^{\circ}$, and $\alpha=27^{\circ}$ as you can see from the equation (1), (2), (3). Extra optimization was done to increase the ratio of light to street side by utilizing the function of the free-form surface within each angle defined by this approach.

$$
\begin{aligned}
& \alpha=9^{\circ}, \quad 40.5<\beta<48 \\
& \alpha=18^{\circ}, \quad 40.5<\beta<48 \\
& \alpha=27^{\circ}, \quad 40.5<\beta<48
\end{aligned}
$$

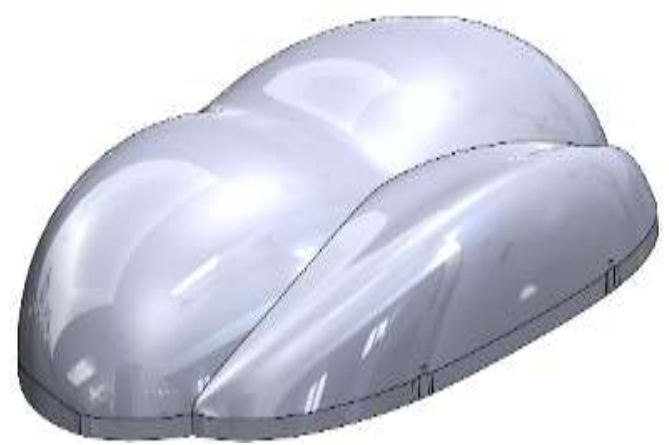

(a) Diagonal view

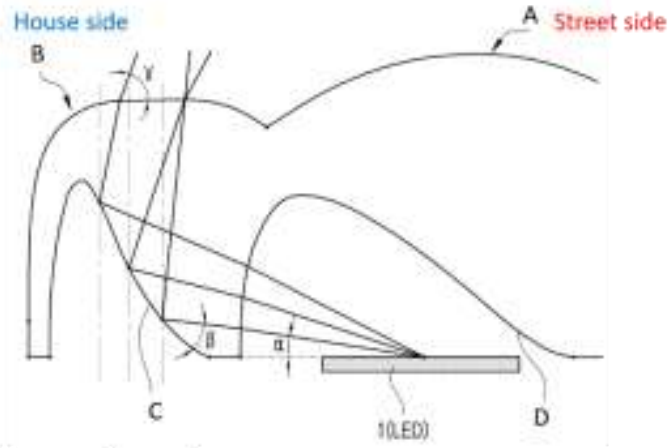

(b) Lens shape with direction of ray Figure 1: Lens shape

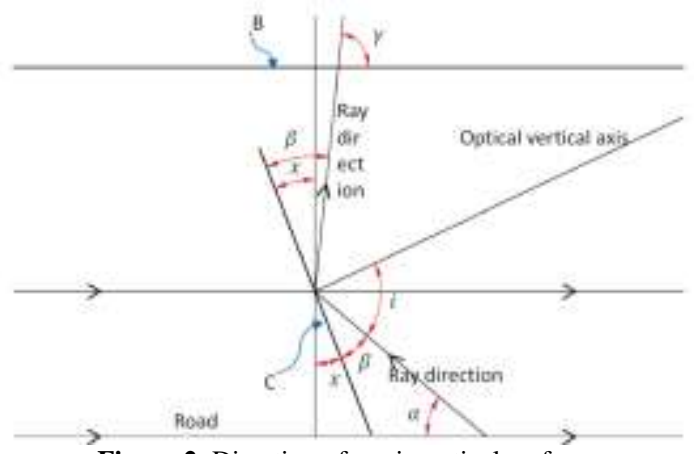

Figure 2: Direction of ray in optical surface

\section{Analysis of Simulation Result}

\subsection{Rating of BUG}

Illuminating Engineering Society of North America IESNA provides the standard of BUG rating at TM-15-11[10]. B stands for backlight, which means the proportion of light going behind the light pole, $U$ stands for uplight, it indicates proportion of light going on the light pole, and $\mathrm{G}$ indicates the degree of glare. The detailed classification is shown in the Figure 3 . The part of the light going forward is divided in to FVH, FH, FM, FL depending 
on the angle, and likewise the backward light part is also divided in to $\mathrm{BVH}, \mathrm{BH}, \mathrm{BM}, \mathrm{BL}$ by distribution angle. Based on the four evaluations, this study analyzes backlight evaluation based on the provisions of backlight regarding this standard provided by IESNA.

Backlight refers to all the light trespassing behind the fixture from the light source towards the ground. In most cases, backlight is an area not originally intended to be lit. In order to analyze light pollution by backlight, backlight is classified into all six grades from B0 to B5 evaluation as shown in Table 1. The maximum lumens value in each area is show from the table in B1 grade. When lumens value in each area is smaller than standard value in table, it corresponds to B1 grade. In this paper it suggests Lens with $50 \mathrm{~W}$ security LED light which satisfy $\mathrm{B} 1$ grade.

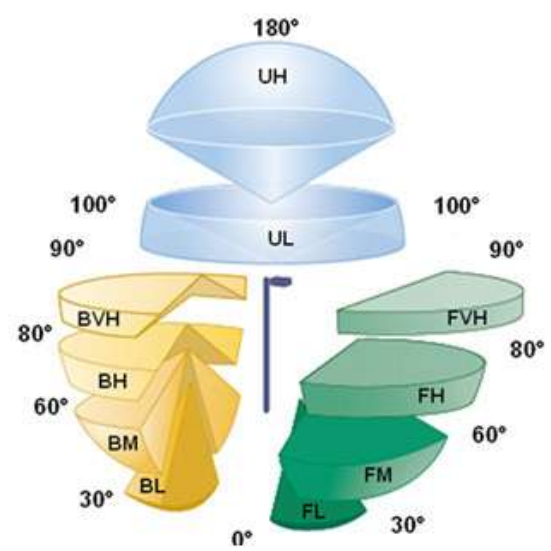

Figure 3: Flux distribution by solid angle

Table 1: Backlight Rating
\begin{tabular}{|l|l|l|l|l|l|l|}
\hline Angle & B0 & B1 & B2 & B3 & B4 & B5 \\
\hline BH & 110 & 500 & 1000 & 2500 & 5000 & $>5000$ \\
\hline BM & 220 & 1000 & 2500 & 5000 & 8500 & $>8500$ \\
\hline BL & 110 & 500 & 1000 & 2500 & 5000 & $>5000$ \\
\hline
\end{tabular}

\subsection{Optical Simulation Result}

\subsubsection{Street Side, House Side Light Distribution}

The size of the light source was chosen as $\varnothing 14(\mathrm{~mm})$, with a power consumption of $50 \mathrm{~W}$ and an efficiency of $150 \mathrm{~lm} / \mathrm{W}$, a total flux of $7000 \mathrm{~lm}$ was output. The simulation was done in two cases. It compared two simulations of a free-form surface lens and a lens with a backlight-controlled surface on a free-form surface. Figure 4 shows the light distribution graph of each two simulations. The green graph is showing the brightness value extending along the horizontal axis in far field's 90 degrees graph, that is, the left and right of the illumination. Graphs of other colors indicate the brightness in the direction of 80 degrees, 70 degrees, etc., respectively. When looking through the intensity chart, the vertical axis refers to the vertical direction, the right is the front direction, that is, the lane side, and the left is the backward direction, that is, the house side. In the simulation of the lens with the additional surface, the graph was shifted forward from the result of the lens simulation before applying the additional surface in the red 80 degrees graph and the blue 70 degrees graph. Figure 6 is a graph of the amount of light spreading on the street side and the house side according to the mounting heights. Table 2 also shows the information in figure 5 more accurately. The lens with only a freeform surface is directed to the house side by an amount of 1825 $\mathrm{lm}$, which is about $26 \%$ of the total luminous flux. A simulation result of a lens with an additional curved surface padded to a freeform surface shows that $1404 \mathrm{~lm}$, which is $20 \%$ of the total luminous flux, is directed to the house side. A light amount of about $420 \mathrm{~lm}$, which is $6 \%$ of the total light amount, turned forward.

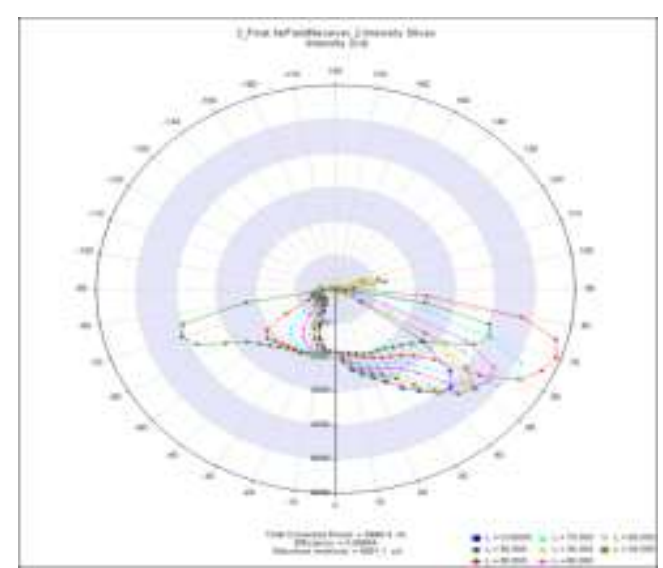

(a) Free from Lens

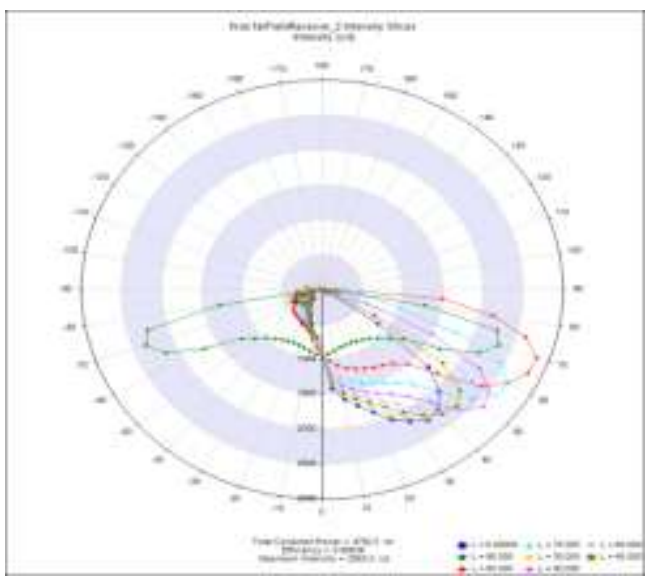

(b) Free from Lens shape with additionalsurface Figure 4: Intensity chart

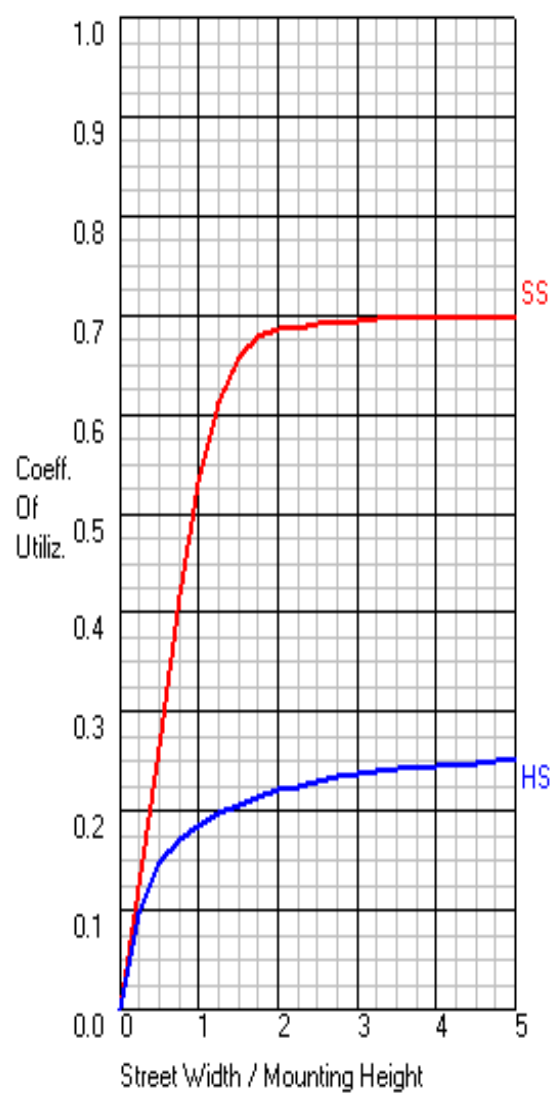

(a) Free from Lens 


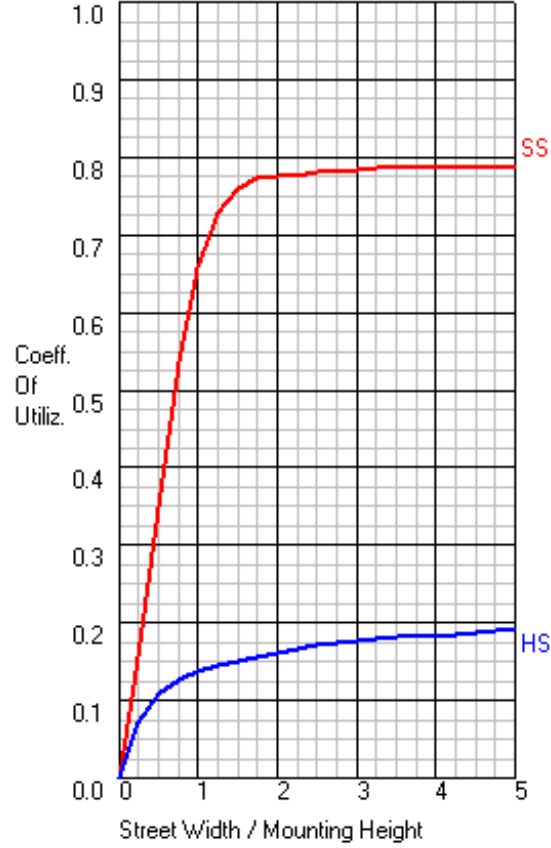

(b) Free from Lens shape with additionalsurface Figure 5: CU Graph

Table 2: Flux Distribution in Each Area

\begin{tabular}{|l|l|l|l|l|}
\hline \multirow{2}{*}{\begin{tabular}{l} 
Area in $\begin{array}{l}\text { irradiated } \\
\text { surface }\end{array}$ \\
\cline { 2 - 5 }
\end{tabular}} & $\begin{array}{l}\text { Fum } \\
\text { ens }\end{array}$ & $\begin{array}{l}\text { Percent of } \\
\text { lumens(\%) }\end{array}$ & Lumens & $\begin{array}{l}\text { Percent of form } \\
\text { lumens(\%) }\end{array}$ \\
\hline $\begin{array}{l}\text { Downward } \\
\text { Street Side }\end{array}$ & $\begin{array}{l}5562 \\
.2\end{array}$ & 79.5 & 4933.5 & 70.5 \\
\hline $\begin{array}{l}\text { Downward } \\
\text { House Side }\end{array}$ & $\begin{array}{l}1404 \\
.8\end{array}$ & 20.1 & 1825.1 & 26.1 \\
\hline $\begin{array}{l}\text { Downward } \\
\text { Total }\end{array}$ & 6967 & 99.5 & 6758.6 & 96.6 \\
\hline $\begin{array}{l}\text { Upward Street } \\
\text { Side }\end{array}$ & 13.3 & 0.2 & 201.7 & 2.9 \\
\hline $\begin{array}{l}\text { Upward House } \\
\text { Side }\end{array}$ & 10.5 & 0.2 & 33 & 0.5 \\
\hline Upward Total & 23.8 & 0.3 & 234.7 & 3.4 \\
\hline Total Flux & 6990 & 99.9 & 6993.3 & 99.9 \\
\hline
\end{tabular}

\subsubsection{Backlight Rating in IESNA}

The LCS graph in Fig. 6 is a graph showing the amount of light incident on the respective regions divided into FL, 0 to 30 degrees FL, 30 to 60 degrees FM, 60 to 80 degrees FH, and 80 to $90 \mathrm{FVH}$ in the forward direction. Backward direction is the same. Simulation results show that the most light is emitted in the FM direction in the Forward direction and the most light is emitted in the BM direction in the backward direction. The important thing to note in these graphs is the BM area. In the simulation of the lens with only a free-form surface, the light to the BM area occupies $10.6 \%$ of the total and $40 \%$ of the backward. Therefore, it is reflected in the design to control the $30 \sim 60$ degrees outgoing light when adding the additional curved surface and sending the backlight forward.

As a result, the simulation of the lens with the added curved surface results in $7.5 \%$ of the diverging light pointing to the BM area, and in the conventional simulation results, the light intensity in the $\mathrm{BH}$ area exceeded $500 \mathrm{~lm}$ and was rated B2 in BUG Rating. In the post-simulation results, the luminous flux of $\mathrm{BH} 4591 \mathrm{~m}$ is diverged and corresponds to $\mathrm{B} 1$ grade.

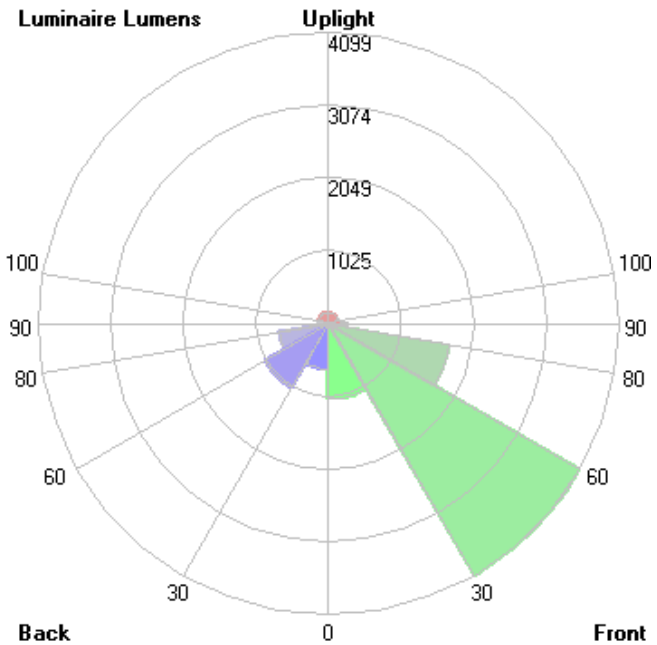

(a) Free from Lens

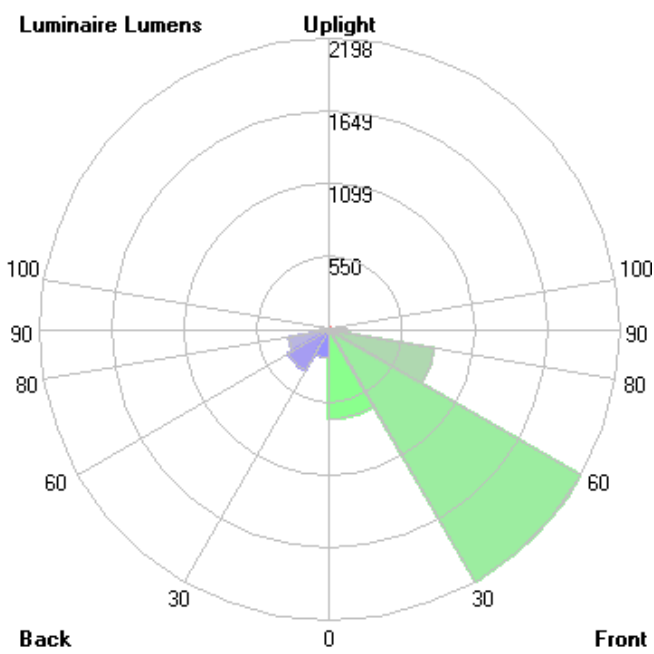

(b) Free from Lens with additionalsurface

Figure 6: LCS Graph

Table 3: Luminaire result based by LCS zone

\begin{tabular}{|l|l|l|l|l|l|}
\hline \multirow{2}{*}{$\begin{array}{l}\text { LC } \\
\text { S }\end{array}$} & \multirow{2}{*}{ Zone } & $\begin{array}{l}\text { Freeform lens } \\
\text { Value of flux } \\
\text { (lm) }\end{array}$ & $\begin{array}{l}\text { Rati } \\
\text { o of } \\
\text { flux } \\
(\%)\end{array}$ & $\begin{array}{l}\text { Falue of flux } \\
\text { surface }\end{array}$ & $\begin{array}{l}\text { Ratio of flux } \\
(\%)\end{array}$ \\
\hline FL & $(0-30)$ & 690.4 & 9.9 & 984 & 14.1 \\
\hline FM & $(30-60)$ & 2772.2 & 39.6 & 3204.8 & 45.8 \\
\hline FH & $(60-80)$ & 1270.4 & 18.1 & 1175.7 & 16.8 \\
\hline $\begin{array}{l}\text { FV } \\
\text { H }\end{array}$ & $(80-90)$ & 200.4 & 2.9 & 197.8 & 2.8 \\
\hline BL & $(0-30)$ & 462.2 & 6.6 & 314.3 & 4.5 \\
\hline BM & $(30-60)$ & 745 & 10.6 & 527.8 & 7.5 \\
\hline BH & $(60-80)$ & 505.3 & 7.2 & 459.9 & 6.6 \\
\hline $\begin{array}{l}\text { BV } \\
\text { H }\end{array}$ & $(80-90)$ & 112.6 & 1.6 & 102.7 & 1.5 \\
\hline UL & $(90-$ & 109.2 & 1.6 & 23.8 & 0.3 \\
\hline UH & $\begin{array}{l}(100- \\
180)\end{array}$ & 125.5 & 1.8 & 0 & 0 \\
\hline $\begin{array}{l}\text { Tot } \\
\text { al }\end{array}$ & & 6993.2 & 99.9 & 6990.8 & 99.9 \\
\hline
\end{tabular}

\section{Conclusion}

In this paper, we propose the control of the back light by using only the lens in the light pollution, suggesting serious problem of light pollution and its effect on the human body.There are many cases in which conventional reflectors are used to control 
backlight in existing streetlights and security. If it is possible to control only this with a lens, there are advantages in increasing the efficiency of the illumination and reducing the cost.An additional surface of the optical system was padded so that total internal reflection occurred in the lens, and the outer surface was set so that the totally reflected light was changed in the forward direction.As a result of, it proposes a lens that makes B1 class light distribution in 50W LED security light.

\section{References}

[1] Liu, M., Zhang, B.G., Li, W.S., Guo, X.W., \& Pan, X.H (2017).Measurement and distribution of urban light pollutionas day changes to night. Light. Res. Technol.

[2] Kent, M.G. (2016).Temporal Effects in Glare Response. Ph.D Thesis, University of Nottingham, Nottingham, UK.https://www.sciencedirect.com/science/article/pii/S0360132316 303444

[3] Touitou, Y., Reinberg, A., \& Touitou, D. (2017). Association between light at night, melatonin secretion, sleep deprivation, and the internal clock: Health impacts and mechanisms of circadian disruption. Life $\quad$ Sci., 193 , 94-106. https://www.ncbi.nlm.nih.gov/pubmed/28214594

[4] Sugden, D. (1989). Melatonin biosynthesis in the mammalian pineal gland. Cell. Mol. Life Sci., 45, 922 932.https://www.ncbi.nlm.nih.gov/pubmed/2572451

[5] Weinert, D., \&Waterhouse, J. (2017). Interpreting Circadian Rhythms. In Biological Timekeeping: Clocks, Rhythms and Behaviour; Springer: New Delhi, India, 23 45.https://www.springer.com/br/book/9788132236863

[6] Bermudez, E.B., Klerman, E.B., Czeisler, C.A., Cohen, D.A., Wyatt, J.K., \& Phillips, A.J. (2016). Prediction of vigilant attention and cognitive performance using self-reported alertness, circadian phase, hours since awakening, and accumulated sleep loss. PLoS ONE, 11.https://www.ncbi.nlm.nih.gov/pubmed/27019198

[7] Hong Soo Lim, Jack Ngarambe, Jeong Tai Kim, Gon Kim. (2018). The Reality of Light Pollution: A Field Survey for the Determination of LIghting Environmental Management Zones in South Korea. Sustainability, 10, 374 http://www.mdpi.com/2071$1050 / 10 / 2 / 374$

[8] Joint, I.D. (2010). Model Lighting Ordinance (MLO) with User's Guide; Second Public Review. Illuminating Engineering Society: New York, NY, USA.https://www.usgbc.org/resources/modellighting-ordinance-users-guide

[9] Krop-Benesch, A., \&Kyba, C.(2015). ALAN 2013-Firs International Conference on Artificial Light at Night : Abstracts; Univiersity TU Berlin : Berlin, Germany.http://www.verlustdernacht.de/tl_files/VDN/Literature/V dN-Band4-ALAN_Conference_Book-web.pdf

[10] IES. (2014).Luminaire Classification System for Outdoor Luminaires. IESNA TM15-11, IESNA, USA. 